\title{
DISPERSED IRON OBTAINING BY THE METHOD OF SOLID STATE HYDRIDE SYNTHESIS AND THE PROBLEM OF HYDROPHOBICITY OF METAL
}

\author{
A. G. Syrkov ${ }^{1}$ N. R. Prokopchuk ${ }^{2}$ \\ ${ }^{1}$ St. Petersburg Mining University (St. Petersburg, Russia): \\ 2 Belarusian State Technological University (Minsk, Belarus)
}

E-mail:syrkov_ag@pers.spmi.ru, tnsippm@belstu.by

\section{AUTHOR'S INFO}

A. G. Syrkov, Dr. Eng., Prof., Dept of General and Technical Physics, head of Nanotechnology Center

N. R. Prokopchuk, Dr. Chem.,

Corresponding Member of National

Academy of Sciences of Belarus, Dept.

of Polymer Composite Materials

Key words:

reduction of iron, silicon hydrides, modifiers, hydrophobic powder obtaining, superhydrophobicity.

\section{A B S T R A C T}

The process of obtaining of a dispersed product based on metallic iron, containing a protective carbosiloxane film on the surface, has been investigated and implemented. The structure and composition of the metal product are characterized by modern physical methods, including X-ray phase and X-ray fluorescence analysis, XPS spectroscopy. The influence of the synthesis mechanism, the role of the metal-silicon chemical interaction in the surface layer on the water-repellent and anticorrosion properties of the obtained samples is considered. It was found that the heat resistance of the samples in air and their hydrophobicity, depending on the type of the reduced metal, increase in the order: nickel - copper - iron. It was shown that highly hydrophobic iron-based samples can be obtained by reduction from iron (II) oxide and Olenegorsk superconcentrate. The prospects of the synthesized powders and the method of their preparation for the creation of superhydrophobic materials are shown. A method for obtaining a metal product has been theoretically and experimentally substantiated, where the formation of a metal structure and its protection from an aggressive environment are carried out within a given volume on the same technological unit with a flow-through reactor

\section{Introduction}

The industrial processes of production of metals, including iron, are based not only on using solid reducing agents [1-6], but also on restoring the initial metalcontaining raw materials with various gaseous reagents [7-15]. The mentioned processes are high-temperature $\left(700-1400{ }^{\circ} \mathrm{C}\right)$ and high-energetic $[2,5,13,14]$. The high temperature which is necessary to obtain the metal cause a range of problems: from the need for proper selection of heat-stable materials for the ore reduction (with carbon materials) furnace $[1,4]$ to the intense pollution of the metal with carbon black in the case of the reduction of oxides with hydrocarbon reagents $[12,15]$. According to the authors [15], who studied the reduction of iron oxides in methane environment at the temperature in the range of $700-100{ }^{\circ} \mathrm{C}$, the obtained metals contained more than 30 mass. \% of carbon. Despite the fact that the reduction of iron by gases is widespread in industrial metallurgy in Russia [10] and in foreign countries [11, 12], another undesirable effect of the process may occur: the possibility of gas corrosion of the metal $[16,17]$. Above $700{ }^{\circ} \mathrm{C}$, methane decomposes into carbon and hydrogen, which initiates hydrogen corrosion of the metal, worsening the properties of the metal (hydrogen embrittlement) [17]. In the case of using converted natural gas in the reduction of metal from oxide raw materials, the reaction gas mixture additionally contains carbon monoxide (CO) impurities, which cause carbonyl corrosion of the metal [16].
In addition, iron-based metal powders are used in delicate areas, which often do not require large-scale industrial production. Such areas include molecular surgery (targeted drug delivery and treatment of the body using magnetic carriers - highly dispersed iron powder), catalysis and also the addition of nanostructured iron powder into organopolymer matrix to improve the properties of protective coatings, lubricants, and to create highly hydrophobic materials [18-22].

According to the authors' evaluation [21], in order to satisfy the need of the megalopolis for organosilicon enamels, household chemicals, and lubricants containing surface-modified dispersed iron additives, it is enough to synthesize $250 \mathrm{~kg}$ of the Fe-powder per year. This is due to the fact that the even relatively low content of Fe-powder (less than 1 mass. \%) leads to significant increase in heat resistance, hydrophobicity and antifriction properties (in lubricants) of the modified materials. Thus, the production of $250 \mathrm{~kg}$ of Fe-powder ensures the production of 25 tons of household and industrial chemicals. The synthesis of $250 \mathrm{~kg}$ of dispersed iron per year is a feasible task even for university research laboratory. This was demonstrated in the elaboration of St. Petersburg Mining University [19, 21].

\section{Problem Statement}

A promising way of production of dispersed metals $(\mathrm{Ni}, \mathrm{Fe}, \mathrm{Cu}$ etc.) with regulated surface properties is the method of solid state hydride synthesis (SSHS) of metals 
[22-24]. The method is based on the reduction of solid metal compounds in an open flow system by volatile hydrogen-element compounds $(\mathrm{E}=\mathrm{N}, \mathrm{C}, \mathrm{Si})$ in the its thermal stability region [23]. Today the following compounds have been studied as hydride reducing agents: ammonia, methane, natural gas (after purification in a low-temperature $\left(-160{ }^{\circ} \mathrm{C}\right)$ zeolite trap), monosilane, methyldichlorosilane, and vapor of hydrophobic siliconorganic liquids based on methyl- or ethyl hydride siloxane [21]. Even in the case of simple hydrides with the small sizes of molecules $\left(\mathrm{NH}_{3}, \mathrm{CH}_{4}, \mathrm{SiH}_{4}\right)$, the dissolution of gaseous-state hydrides in the metal lattice during SSHS is uncharacteristic $[16,17,23]$ and thus the possibility of gas corrosion is minimized. Since the temperature of SSHS of metals is $60-100{ }^{\circ} \mathrm{C}$ lower than the temperature of thermal decomposition of the corresponding hydride in the gas phase, hydrogen corrosion of the metal and hardly controlled processes of deposition of carbon or silicon on the metal from the reaction gas phase are almost excluded $[19,23,24]$.

The treatment of metal oxide or metal halides at high temperatures by ammonia, methane or monosilane is used to synthesize nitrides (above $600{ }^{\circ} \mathrm{C}$ ), carbides (above $700{ }^{\circ} \mathrm{C}$ ) or silicides (above $500{ }^{\circ} \mathrm{C}$ ) of iron, respectively [25-27]. It is easy to notice that the synthesis temperatures of these compounds significantly exceed the temperatures of the thermal decomposition of the corresponding hydride in the gas phase: $500{ }^{\circ} \mathrm{C}$ for $\mathrm{NH}_{3}, 700{ }^{\circ} \mathrm{C}$ for $\mathrm{CH}_{4}$, and $400{ }^{\circ} \mathrm{C}$ for $\mathrm{SiH}_{4}$ [28]. The formation of carbon or silicon during thermal decomposition of methane or monosilane, respectively, promotes the formation of metal compounds (carbides or silicides), where the nonmetal atom $(\mathrm{C}$ or $\mathrm{Si})$ is negatively charged [21, 23]. Under SSHS temperature conditions, thermal decomposition of the reducing hydride does not occur; X-ray graphically identifiable phases of metal nitrides, carbides, or silicides are not detected [23]. There is chemisorption of hydride on the metal surface, reliably detected by XPspectroscopy [23, 24]. By varying reducing hydrides, it is possible to change the nature of the metal surface from hydrophilic (in $\mathrm{NH}_{3}$ ) to hydrophobic (in $\mathrm{CH}_{4}$ ) and highly hydrophobic (treatment with organosilicon reagents and $\left.\mathrm{CH}_{4}\right)[21,22]$.

The most studied are the processes of obtaining samples based on nickel and copper under SSHS conditions [21-24]. According to thermodynamic calculations, the reduction of copper dichloride in ammonia, as well as copper (II) oxide in methane are favorable processes above $700 \mathrm{~K}(\Delta \mathrm{G}<0)$ even under equilibrium conditions (Fig. 1). However, under the same conditions, the reduction of $\mathrm{Fe}$ (II) oxide in methane is not a thermodynamically favorable process $(\Delta \mathrm{G}>0)$. Above $700 \mathrm{~K}$ the reduction of iron dichloride is possible (Fig. 1), but in this temperature range, the metal chloride begins to sublimate into the gas phase [26], and the process of reduction ceases proceeding in the solid phase. Since the SSHS process of metals is carried out under conditions far away from equilibrium [23, 24] (in a flow of reducing

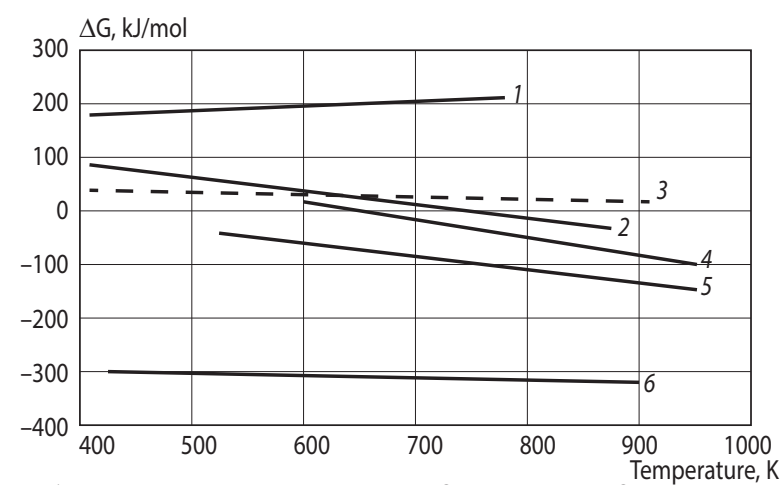

Fig. 1. Temperature dependence of the change of the standard isobaric potential of the reduction reactions of chlorides and metal oxides by hydrides under equilibrium conditions:

$1-4 \mathrm{FeO}+\mathrm{CH}_{4}=4 \mathrm{Fe}+\mathrm{CO}_{2}+2 \mathrm{H}_{2} \mathrm{O}$;

$2-\mathrm{FeCl}_{2}+2 / 3 \mathrm{NH}_{3}=\mathrm{Fe}+1 / 3 \mathrm{~N}_{2}+2 \mathrm{HCl}$;

$3-4 \mathrm{NiO}+\mathrm{CH}_{4}=4 \mathrm{Ni}+\mathrm{CO}_{2}+2 \mathrm{H}_{2} \mathrm{O}$

$4-\mathrm{NiCl}_{2}+2 / 3 \mathrm{NH}_{3}=\mathrm{Ni}+1 / 3 \mathrm{~N}_{2}+2 \mathrm{HCl}$;

$5-\mathrm{CuCl}_{2}+2 / 3 \mathrm{NH}_{3}=\mathrm{Cu}+1 / 3 \mathrm{~N}_{2}+2 \mathrm{HCl}$;

$6-4 \mathrm{CuO}+\mathrm{CH}_{4}=4 \mathrm{Cu}+\mathrm{CO}_{2}+2 \mathrm{H}_{2} \mathrm{O}$

gas), it is theoretically possible, by varying of hydride reducing agents, to lower the temperature conditions and to obtain unique corrosion-resistant metal materials with hydrophobic surface.

The main purpose was to obtain dispersed iron modified in the surface layer by organosilicon compounds under SSHS conditions, to estimate its water-repellent properties, and to compare hydrophobicity with samples based on different metals obtained by various methods.

\section{Experiments and Investigation}

The production of surface-modified metals by SSHS method was carried out on the open flow installation, which includes systems for purification of reducing (methane) and noble-carrier gas (argon) from traces of oxygen and moisture [21, 24]. The synthesis temperature was monitored potentiometrically and kept constant in the isothermal zone (on the grid of the reactor) with an accuracy $\pm 5{ }^{\circ} \mathrm{C}$. Vapor of the silicon hydride reductantmethyldichlorosilane (MDCS) were fed into the reactor in argon flow at a flow rate of no more than $4.2 \times 10^{-6} \mathrm{~m}^{3} / \mathrm{s}$. Fractions of solid-phase metal-containing raw materials with a particle size of $0.5-0.8 \mathrm{~mm}$ were taken for sequential reduction in MDCS vapor and methane. As the initial raw materials powder of chemically pure iron (II) oxide and Olenegorsk superconcentrate (OSC), which is close in composition to $\mathrm{Fe}_{3} \mathrm{O}_{4}$ (99.5\%; GOST 52939-2008), were used. The mentioned iron-containing powders were dried to constant weight in argon flow at a temperature not lower than $340{ }^{\circ} \mathrm{C}$ before filling the reactor with MDCS. Metal formation during SSHS was proved by X-ray diffraction analysis (DRF-2.0 instrument), X-ray photoelectron spectroscopy (VG Escalab iXL instrument) and chemical analysis. The composition of the obtained solid SSHS products was determined by the methods of X-ray fluorescence analysis (Bruker S4 Explorer), EDX spec- 


\begin{tabular}{|c|c|c|c|c|c|c|c|c|}
\hline \multirow[t]{2}{*}{ Sample } & \multicolumn{2}{|c|}{ M, wt. \% } & \multicolumn{2}{|c|}{ Si, wt. \% } & \multirow{2}{*}{$\begin{array}{c}\text { C, wt. \% } \\
\text { Chem. an. }\end{array}$} & \multicolumn{2}{|c|}{$\mathrm{Cl}$, wt. \% } & \multirow{2}{*}{$\begin{array}{c}\text { Si-C } \\
\text { Chem. an }\end{array}$} \\
\hline & Chem. an. & RFA & Chem. an. & RFA & & Chem. an. & RFA & \\
\hline $\mathrm{NiCl}_{2}+\mathrm{MDCS}+\mathrm{CH}_{4}$ & $96.0 \pm 0.1$ & - & $2.3 \pm 0.2$ & - & $1.6 \pm 0.1$ & $0.1 \pm 0.001$ & - & 3.4 \\
\hline $\mathrm{NiO}+\mathrm{MDCS}+\mathrm{CH}_{4}$ & $95.8 \pm 0.3$ & 95.6 & $2.4 \pm 0.1$ & 2.0 & $1.7 \pm 0.1$ & $0.05 \pm 0.03$ & - & 3.4 \\
\hline $\mathrm{CuO}+\mathrm{MDCS}+\mathrm{CH}_{4}$ & $95.3 \pm 0.1$ & 94.9 & $2.3 \pm 0.7$ & - & $1.4 \pm 0.2$ & $0.09 \pm 0.01$ & 0.084 & 3.3 \\
\hline $\mathrm{FeO}+\mathrm{MDCS}+\mathrm{CH}_{4}$ & $94.5 \pm 0.5$ & - & $0.8 \pm 0.4$ & - & $1.4 \pm 0.2$ & $0.06 \pm 0.03$ & - & 1.5 \\
\hline
\end{tabular}

troscopy (analytical attachment EDAX/TSL to electron microscope Nanolab). The determination of the adsorption of water vapor on the samples was carried out gravimetrically by the desiccator method at a temperature of $20 \pm 2{ }^{\circ} \mathrm{C}$. Mathematical description of the results and spectral dependences was carried out using MathCAD and Origin 6.0 software.

\section{Results and Discussion}

Our earlier studies showed that reduction of $\mathrm{Cu}$ (II), $\mathrm{Ni}$ (II) and Fe (II) oxides to metal at SSHS temperatures in methane $\left(500-650{ }^{\circ} \mathrm{C}\right)$ or in monosilane $\left(320-340{ }^{\circ} \mathrm{C}\right)$ do not provide serious results [21, 23]. Possible reason is the absence of $\mathrm{CH}_{4}$ adsorption on solid oxide due to energy and steric factors [23]. Chemisorption of $\mathrm{CH}_{4}$, which precedes the reduction of oxide [2], is determined by the distance between the neighboring oxygen on the surface of the solid oxide and the size of the methyl group (about $0.3 \mathrm{~nm}$ ) [29]. The similar distance between surface bonded oxygen atoms $(0.26-0.3 \mathrm{~nm})$ appears for $\mathrm{Fe}_{2} \mathrm{O}_{3}$.

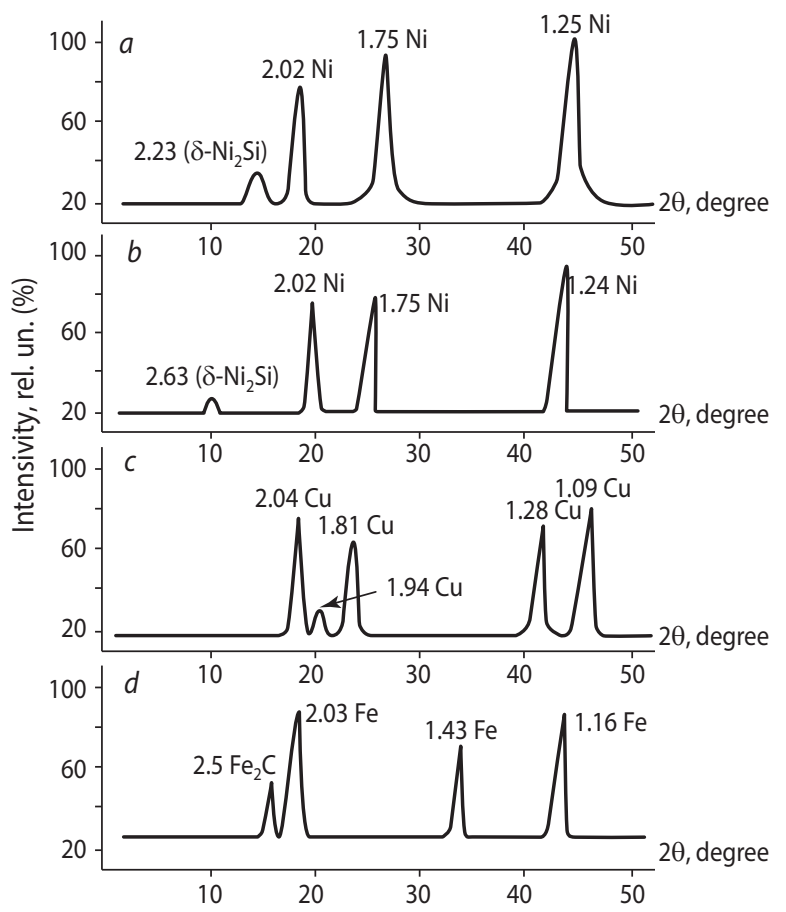

Fig. 2. The XR diffraction patterns of solid SSHS products obtained by sequential reduction of metal-containing raw materials in $\mathrm{MDCS}$ vapor $\left(340^{\circ} \mathrm{C}\right)$ and methane $\left(600{ }^{\circ} \mathrm{C}\right)$, from:

$a-\mathrm{Ni}$ (II) chloride; $b-\mathrm{Ni}$ (II) oxide; $c-\mathrm{Cu}$ (II)

oxide; $d-\mathrm{Fe}$ (II) oxide
However, due to thermodynamic instability of $\mathrm{Fe}$ (II) oxide below $580{ }^{\circ} \mathrm{C}$ the distance can be noticeably higher [30], which prevents dissociative chemisorption of $\mathrm{CH}_{4}$ on solid surface [21, 29].

The problem of quantitative and deep reduction of $\mathrm{Fe}$ (II) oxide, as well as Ni and $\mathrm{Cu}$ oxides, is solved by using MDCS (alkyl-chlorine derivative of monosilane) as a hydride reagent. From the XR diffraction patterns (see Fig. 2, $d$ ) it follows that upon the reduction of Fe (II) oxide under SSHS conditions, a metallic Fe- $\alpha$ phase with $d=2.03, d=1.43$ and $d=1.16$ is formed. Within a few percent broadening of the diffraction maxima is observed. It caused by the dispersion of the ironbased product (specific surface area of $1 \mathrm{~m}^{2} / \mathrm{g}$, submicron size of particle aggregates). The final stage of the treatment of the sample in methane under heating is necessary to remove chlorine, which is adsorbed in the first stage of reduction in MDCS vapor.

During the reduction of iron, nickel and copper, the contribution of competing processes of siliconizing and carbidization of metal metal is minimized. In the XRD patterns (Fig. 2) there is no necessary set of analytical diffraction maxima, which is needed to identify the known crystalline phases of silicides or carbides of the metals. There are only single peaks of low intensity, which can be attributed to the lowest silicide of nickel (Fig. 2, $a, b$ ) or copper (Fig. 2,c). In addition to the analytical diffraction maxima of metallic iron in the XRD pattern the obtained iron product (Fig. 2, $d$ ) has a line $\mathrm{d}=2.15$ with several times lower intensity, which is most suitable for $\mathrm{Fe}_{2} \mathrm{C}$.

In terms of data in Table 1, only the surface siliconization of nickel and copper or carbonization of the iron surface could occur. The carbon content of Fe-product of SSHS, is 1.4-1.6 wt. \%, and the carbon content of $\mathrm{Fe}_{2} \mathrm{C}$ is about $10 \%$. The silicon content of the $\mathrm{Fe}$ - product $(0.8 \mathrm{wt} . \%$, see Table 1$)$ is 16 times less than the silicon content of the lower silicide $-\mathrm{Fe}_{3} \mathrm{Si}(13 \mathrm{wt} . \%)$.

In our research, the enhancement of the reducing properties of MDCS in comparison with monosilane during gas-phase treatment of $\mathrm{Ni}, \mathrm{Fe}$, and $\mathrm{Cu}$ oxides is associated with the intermediate stage of chlorination of the initial solid reagent $[21,23]$. The fact of oxide chlorination during the reduction of $\mathrm{Fe}$ (II) oxide and iron oxide concentrate (OSC) was confirmed experimentally (X-ray structural and chemical analysis, X-ray photoelectron spectroscopy) [21]. Metal chlorides are more easily reduced to metal than oxides [26]. Therefore, the treatment of the solid oxide with the bifunctional reagent (MDCS), which has the reduction potential due to $\mathrm{Si}-\mathrm{H}$-groups and chlorinating effect, allows to destroy strong metal-oxide bonds and to obtain iron, nickel and copper in the metallic 
state. Under the SSHS conditions the prevalence of iron carbonization over surface "siliconization" of the metal (characteristic of nickel and copper) can be explained by the good affinity of iron for carbon. The absence of metal carbonization (carbidization) in the case of nickel and copper is associated with the instability of their carbides at a temperature of $600^{\circ} \mathrm{C}$ [27], at which the final stage of reduction in a flow of methane occurs [21].

Here are the gross-reactions of the main processes of the reduction of metal oxide $(\mathrm{M}=\mathrm{Fe}, \mathrm{Ni}, \mathrm{Cu})$ under SSHS conditions, which were discussed above.

Reaction of the oxide reduction process in MDCS vapor:

$$
\begin{aligned}
& 2 \mathrm{MO}+4 \mathrm{CH}_{3} \mathrm{Cl}_{2} \mathrm{SiH} \rightarrow t^{\circ} 2 \mathrm{M}+\left(\mathrm{CH}_{3} \mathrm{ClSiH}\right)_{2} \mathrm{O}+ \\
& +\left(\mathrm{CH}_{3} \mathrm{Cl}_{2} \mathrm{Si}\right)_{2} \mathrm{O}+2 \mathrm{HCl} .
\end{aligned}
$$

Here is the scheme of chemisorption of MDCS oxidation product on metal, confirmed by XPS and IR spectroscopy [24, 31]:

$$
M_{S} \stackrel{\left(\mathrm{CH}_{3} \mathrm{ClSiH}\right)_{2} \mathrm{O}}{\longrightarrow} M_{S}\left[\left(\mathrm{CH}_{3} \mathrm{ClSiH}\right)_{2} \mathrm{O}\right]_{a d s} .
$$

Here is the scheme of reduction (dechlorination) of the solid product of the previous stage with a chemisorbed organosilicon compound in methane:

$$
M_{S}\left[\left(\mathrm{CH}_{3} \mathrm{ClSiH}\right)_{2} \mathrm{O}\right]_{a d s} \stackrel{\mathrm{CH}_{4}, t^{\circ}}{\longrightarrow} M_{S} \underset{\mid}{\mathrm{Si}-\mathrm{O}-\mathrm{Si}-]_{a d s}}
$$

According to the data in Table 2, the reduction of the iron ore oxide concentrate OSC under SSHS conditions leads to a significant hydrophobic effect of the resulting solid product. Water adsorption drops by almost 30 times (5.4 and 0.19 wt.\%). It is interesting that during the first day of sorption of saturated water vapor, the sample
$\left(\mathrm{OSC}+\mathrm{MDCS}+\mathrm{CH}_{4}\right)$ did not add, but lost (at the level of 0.9 wt. \%) in mass. The sample is poorly wetted by water. The particles are capable of not settling on the bottom of a container filled with water for a long (Table 2).

The hydrophobicity of fresh iron-based samples obtained by the SSHS method is significantly higher than hydrophobicity of carbonyl nickel iron treated with the industrial organosilicon hydrophobizator HSL-94 (Ni/ HSL), as well as powders of (P10), nickel (PNK-UTZ) and copper (PM-1), treated in various combinations of HSL-94 and reagents with hydrophobic organic groups alkamone (A) and triamone (T). This is confirmed by the data in Table 3. The value of water vapor absorption by the sample obtained from iron (II) oxide under SSHS conditions is $16 \mu \mathrm{mol} / \mathrm{m}^{2}$, which is two orders of magnitude less than the water absorption of metal powders modified with hydrophobizing agents. The water absorption of this Fe sample is at the corresponding level of highly hydrophobic organosilicon adsorbents synthesized at Kiev Scientific School (14-16 $\left.\mu \mathrm{mol} / \mathrm{m}^{2}\right)$ [32].

Today, the problem of obtaining highly hydrophobic materials (including metal-based) is rapidly developing in Russia and abroad [33, 34]. Leading experts in this field recommend application of perfluorooxysilane, various fluorine-containing copolymers and polydimethylsiloxanes. The least toxic of these hydrophobic agents are polydimethylsiloxanes, which are silicones. Similar substances are polymerized in the processes of the syntheses (see schemes of gross SSHS processes above).

The feature of our synthesis is that, strong chemical interaction between the metal and the protective film occurs due to the combination in time (on one installation) of the processes of reduction and modification with organosilicon compounds (carbosiloxane structures). Heteroatomic

\begin{tabular}{|c|c|c|c|c|c|c|}
\hline \multirow[t]{2}{*}{ Sample } & \multicolumn{3}{|c|}{$\begin{array}{c}\text { Relative weight gain in } \\
\text { water vapor at } p / p_{s} \rightarrow 1, \%\end{array}$} & \multicolumn{2}{|c|}{$\begin{array}{l}\text { Weight loss after drying } \\
\text { over } \mathrm{P}_{2} \mathrm{O}_{5}, \text { wt. \% }\end{array}$} & \multirow[t]{2}{*}{ Note } \\
\hline & 1 day & 2 days & 5 days & 1 day & 5 days & \\
\hline OSC & 0.36 & 3.76 & 5.4 & -0.11 & -0.44 & The sample is hydrophilic \\
\hline $\mathrm{OSC}+\mathrm{MDCS}+\mathrm{CH}_{4}$ & -0.09 & 0.15 & 0.19 & -0.13 & -0.16 & Hydrophobic powder particles float for weeks on the surface of the water \\
\hline
\end{tabular}
electronic interaction $\mathrm{M} \rightarrow \mathrm{Si}$ is confirmed by $\mathrm{X}$-ray photo-

\begin{tabular}{|c|c|c|c|c|c|}
\hline Sample, method of obtaining & $\mathrm{Fe}(\mathrm{II})$ oxide $+\mathrm{MDCS}+\mathrm{CH}_{4}$ & $\mathrm{Ni} / \mathrm{HSL}$ & $\mathrm{Fe} / \mathrm{T} / \mathrm{HSL}$ & $\mathrm{Ni} / \mathrm{T} / \mathrm{A}$ & $\mathrm{Cu} / \mathrm{A} / \mathrm{HSL}$ \\
\hline$a, \mathrm{mmol} / \mathrm{m}^{2}$ & 0.016 & 2.2 & 2.0 & 2.3 & 1.0 \\
\hline
\end{tabular}
electron spectroscopy data from Table 4. The data (binding

\begin{tabular}{|c|c|c|c|c|c|}
\hline$a, \mathrm{mmol} / \mathrm{m}^{2}$ & $\begin{array}{l}\text { The compound from which } \\
\text { the metal is reduced }(\mathrm{M})\end{array}$ & $\mathrm{S}_{\mathrm{SSA}}, \mathrm{m}^{2} / \mathrm{g}$ & $\begin{array}{c}\mathrm{K}, \mathrm{mg} / \mathrm{cm}^{2} \\
\left(900^{\circ} \mathrm{C}, 100 \mathrm{~h}\right)\end{array}$ & $\mathrm{E}_{\mathrm{si2p}, \mathrm{eV}}$ & $\Delta$ forM $2 p_{3 / 2}, e V$ \\
\hline 0.027 & $\mathrm{Ni}$ (II) chloride & 11 & 0.00051 & 104.8 & 2.4 \\
\hline 0.030 & $\mathrm{Ni}$ (II) oxide & 57 & 0.00042 & 105.7 & 1.4 \\
\hline 0.024 & $\mathrm{Cu}$ (II) oxide & 12 & 0.00033 & 103.8 & 2.5 \\
\hline 0.016 & Fe (II) oxide & 1 & 0.00011 & 102.4 & 4.9 \\
\hline
\end{tabular}
energy $\mathrm{Si} 2 \mathrm{p}$ level and $\Delta-$ chemical shift of $\mathrm{M} 2 \mathrm{p}_{3 / 2}$ level) 


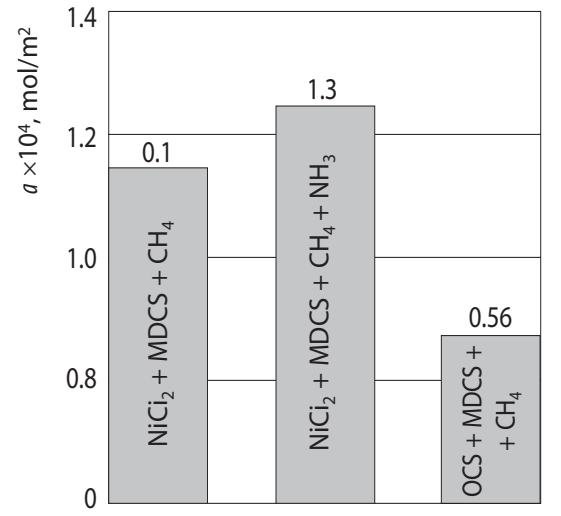

Fig. 3. Absorption of saturated water vapor $\left(\mathrm{p} / \mathrm{p}_{\mathrm{s}} \rightarrow 1\right)$ by samples based on nickel and iron synthesized by the SSHS method. Samples were stored for 30 years in buckets

shows the importance of chemisorption of carbosiloxane groups on chemically active metal centers, which provides high hydrophobicity of the samples and high heat stability in air with an increase in mass (K) at a level of $0.1-0.4 \mu \mathrm{g} /$ $\mathrm{cm}^{2}$. For high-quality nickel-chromium alloys, the heat resistance under the same conditions is about $7 \mu \mathrm{g} / \mathrm{cm}^{2}$, which is 70 times worse than that of the Fe sample obtained under SSHS conditions (Table 4). Even after 30 years of storage (Fig. 3) the Fe sample obtained from OSC remains the leader and is almost 2 times more hydrophobic than Ni samples obtained under the same conditions (SSHS).

SSHS fulfills at least two important goals. It returns to the metal its "original" property inherent in the atomically pure metal surface - hydrophobicity [16, 35]. Base metals in a real air atmosphere are rapidly oxidized, and their surface becomes hydrophilic [16, 35, 36]. In addition, the demonstrated SSHS method allows to synthesize a set of chemically stable dispersed metal materials which are perspective for solving the problem of superhydrophobicity and corresponding applications [33,34]. According to experts, in order to create superhydrophobic materials and coatings, it is preferable to use solid-state systems with bimodal particle size distribution, for example, substrate with micro- and macro-sized structural elements and hydrophobic substance nanofilm with adhesion to the substrate. The obtained $\mathrm{Fe}-, \mathrm{Ni}-$, and $\mathrm{Cu}$-samples correspond perfectly with this model. The metal substrate consists of aggregates of micron-sized particles [31] with a chemically interacting carbosiloxane protective film (no more than 4-5 nm thick) [23, 24] (see Table 4). Chemical resistance and hydrophobicity of the synthesized powders enhances depending on the nature of the metal in the series $\mathrm{Ni}, \mathrm{Cu}, \mathrm{Fe}$. These powders have been applied at the enterprises of the mineral resource complex in the Russian Federation and in the Republic of Belarus [21, 37], including PJSC "Belgorkhimprom", PJSC "Soligorsk Institute of Resource Saving Problems with Pilot Production" (Belarus), Research Institute "Energostal", company "GMC", LLC "GSK-Shakhtproekt" (Russia). According to these organizations experts, the economic effect of using powders as components of protective coatings and lubricants makes on average $7-10 \mathrm{mln}$ rubles/year [21, 31].
It is important to underline the possibility of using the Olenegorsk superconcentrate (OSC) in SSHS technology. Fields of raw materials for OSC in North-West Russia are estimated at millions of tons. OSC is a product of magnetite concentrate refinery. OSC is a finely dispersed black powder, which is easily, can be grind to particles of 30 microns and below. The specific surface area of OSC is about $10 \mathrm{~m}^{2} / \mathrm{g}$. The water content is at the level of $0.5-1.0 \mathrm{wt} \%$. The OSC price on the domestic market (May 25, 2020) is 66.3 USD per ton. Recalculated in rubles, the price for $1 \mathrm{~kg}$ of OSC is less than 5 rubles ( 4.95 rubles $/ \mathrm{kg}$ ). The use of such iron oxide raw materials is very beneficial, since its price is an order of magnitude lower than reactive purity iron oxide. Another advantage of OSC is that it is used in metallurgy in the production of iron powders of almost all grades in accordance with GOST 9849-74.

The obtained results supplement and develop the theory and practice of metallurgical processes of synthesis of new materials (based on iron and other metals) with improved properties, and also contribute to the modern research of the scientific school of metallurgists of Mining Institute (now the University) in St. Petersburg [38-44], at the origins of which was academician N.S. Kurnakov [21, 24, 45, 46].

\section{Conclusions}

The obtaining of dispersed iron containing a carbosiloxane protective film chemically bonded to the metal in the surface layer has been theoretically and experimentally substantiated. The metal content is $94.5 \%$, silicon is about $1 \%$, carbon is $1.4 \%$, oxygen is not more than $2 \%$. The specific surface area of the solid product is in the order of $1 \mathrm{~m}^{2} / \mathrm{g}$. The water absorption of the sample in saturated water vapor is at the level of $16 \mu \mathrm{mol} / \mathrm{m}^{2}$ when tested for up to $200 \mathrm{~h}$. Heat stability in air is about $0.1 \mu \mathrm{g} / \mathrm{cm}^{2}$ at $900{ }^{\circ} \mathrm{C}$ for $100 \mathrm{~h}$ at atmospheric pressure and free air access.

The water-repelling properties and heat stability in air of samples based on iron, nickel, and copper obtained from oxides under SSHS conditions by their successive reduction with methyldichlorosilane vapor and methane are compared. It was found that, depending on the type of metal, the hydrophobicity and corrosion resistance of the samples increases in the following order: nickel - copper - iron.

It was found that the improved characteristics of the samples in terms of hydrophobicity and corrosion resistance correspond to the strongest chemical interaction between metal and silicon, which, according to XPS spectroscopy data, is found in the sample based on iron.

It has been shown that not only a chemically pure reactants of bivalent iron oxide, but also a much cheaper Russian-made Olenegorsk superconcentrate (OSC), can be used as the initial iron oxide raw material for obtaining surface-modified iron powders with improved properties.

The prospects for the use of synthesized metal powders for the creation of superhydrophobic materials are analyzed. Some of the obtained dispersed samples based on metallic iron and other metals have already found application at en- 
terprises in Russia and Belarus for solving problems of equipment protection and lubrication.

A method for the synthesis of the metal product has been implemented, which is characterized by the complex production of a metal structure and its protection within a given volume on one technological unit (in a flow reactor). Modification of the metal surface with carbosiloxane structures containing thermo- and chemically resistant $\mathrm{Si}-\mathrm{C}$ bonds occurs not during the application of modifiers to the prepared metal surface, but directly during the reduction of the initial solid metal compound (ore) with an organosilicon reagent. The metal, in our opinion, at the moment of its appearance, actively interacts with a reducing agent containing $\mathrm{Si}-\mathrm{H}$ groups, with the formation of a chemical bond with the applied protective carbosiloxane film.

\section{Acknowledgements and Dedication}

The authors dedicate this article to blessed memory and to the 70th anniversary of the birth of Ilya Nikitich Beloglazov (1950-2011), a famous metallurgist, scientist-encyclopaedist. One of the authors of this article worked with him on interesting projects in 2003-2011, including those organized by the "Ore and Metals" Publishing House: writing one of the first Russian monographs on nanomaterials, preparing a special thematic issue "Nanostructured Metals and Materials" within "Tsvetnye metally" journal, including its English version "Non-ferrous metals" [20], writing articles for the journal "CIS Iron \& Steel Review" (2008), as well as organizing and conducting the International Symposium "Nanophysics and Nanomaterials" (since 2003). It is important to note with gratitude that most of these projects, inspired by the energy of Professor I.N. Beloglazov, continue to function to this day, contributing, among other things, the strengthening of scientific cooperation of specialized universities of the Union State.

\section{REFERENCES}

1. Bogdandi L., Engel G.-U. Reduction of iron ores. Moscow: Metallurgiya, $1971.520 \mathrm{p}$

2. Popel S. I., Sotnikov A. I., Boronenkov V. N. Theory of metallurgical processes. Moscow: Metallurgiya, 1986. 463 p.

3. Leontiev L. I., Sheshkunov O. Yu., Nekrasov I. V. Analysis, processing and use of industrial wastes of metallurgical production. Kompleksnoe ispolzovanie mineralnogo syrya. 2014. No. 4. pp. 8-25.

4. Tleugabulov S. M., Abikov S. B., Koyshina G. M., Tatybaev M. K. Reduction melting of steel: Basics and prospective development. Metally. 2018. No. 2. pp. 72-77.

5. Sasuntsyan M. E. High-temperature synthesis of the iron monosilicide from production slags. Proc. RA NAS and SEUA. Ser. TH. 2018. Vol. 71. No. 1. pp. 3-9.

6. Puchkov L. A., Vorobiev A. G., Fedina O. V. "Gornyi Zhurnal" and development of mining in Russia. Gornyi zhurnal. 2015. No. 7. pp. 5-12.

7. Anacleto N. M., Solheim I., Serensen B., Ringdalen E., Ostrovski O. Reduction of chromium oxide and ore by methane-containing gas mixture. Authors' Revised Draft Infacon XV: International Ferro-Alloys Congress, Southern African Institute of Mining and Metallurgy, Cape Town, 25-28 February 2018. pp. 71-78.
8. Leikola M., Taskinen P., Eric R. H. Reduction of Kemi chromite with methane. Authors' Revised Draft Infacon XV: International Ferro-Alloys Congress, Southern African Institute of Mining and Metallurgy, Cape Town, 25-28 February 2018. pp. 79-84.

9. Bondarenko B. I. Reduction of metal oxides in complicated gas systems. Kiev: Naukova Dumka, 1980. 385 p.

10. Theory and practice of direct obtaining of iron. Edited by A. I. Manokhin. Moscow: Nauka, 1986. 272 p.

11. Schenck J., Lüngen H. B. Potentials of direct and smelting reduction processes for an efficient application in Europe. Chernye Metally. 2017. No. 2. pp. 25-31.

12. Duarte P., Becerra J. Production of high-carbon directly reduced iron at Tenova Hyl. Chernye Metally. 2016. No. 6. pp. 24-30.

13. Paton B. E. Science. Techniques. Progress. Moscow: Nauka, 1987. $360 \mathrm{p}$.

14. Kriklivyi D.I., Klimovich N.A. Research of activity of gas reducers and methods of their selection in high-temperature processes. Zhurnal Prikladnoy Khimii. 1991. Vol. 64. No. 11. pp. 2242-2249.

15. Hadzhikov A. S., Harlamin P. S., Hazhinova N. S. Kinetics and mechanism of interaction of iron oxides with methane. Proc. of IX All-Union conference on Kinetics and mechanism of chemical reactions in solids. Chernogolovka. 1986. Vol. 2. pp. 159-160.

16. Fast J. Interaction metals with gases. Vol. 2. Moscow: Metallurgiya, $1975.351 \mathrm{p}$.

17. Malakhov A. I., Zhukov A. P. Bases of metal science and theory of corrosion. Moscow: Vysshaya Shkola, 1978. 191 p.

18. Roco M. C., Bainbridge W. S. Societal Implication of Nanoscience and Nanotechnology. Dordrecht: Kluwer Acad. Publ. 2001. $384 \mathrm{p}$.

19. Yartsev I., Pleskunov I., Syrkov A., Bystrov D. Interrelation of water-repellent and protective properties of coatings on steel and role of nanostructured additives. CIS Iron and Steel Review. 2008. Vol. 3. pp. 26-29.

20. Beloglazov I. N., Syrkov A. G. Nano-structured Metals and Materials: Urgency of Problems and Availability of Investigations. Non-Ferrous Metals. 2006. No. 4. pp. 3-5.

21. Syrkov A. G., Bazhin V. Yu., Mustafaev A. S. Nanotechnology and Nanomaterials: Physical and mineral resources aspects. Saint Petersburg: Polytech-Press, 2019. 244 p.

22. Meretukov M. A., Tsepin M. A., Vorobiev S. A., Syrkov A. G. Clusters, structures, materials of nanosize: innovative and technical prospective. Moscow: Ruda i Metally, 2005. 128 p.

23. Syrkov A. G. Regularities of hydride solid-state synthesis of metallic substances and compounds. Russian Journal of Inorganic Chemistry. 1993. Vol. 38. No. 5. pp. 753-759.

24. Syrkov A. G. Novel ways and fundamentals of metals nanotechnology. Tsvetnye Metally. 2004. No. 4. pp. 67-71.

25. Properties, obtaining and use of refractory compounds. Moscow: Metallurgia, 1986. 928 p.

26. Korshunov V. G., Stefanyuk S. A. Introduction in chlorine metallurgy. Moscow: Metallurgiya, 1970. 343 p.

27. Kosolapova T. Ya. Carbides. Moscow: Metallurgiya, 1968. 299 p.

28. Zhigach A. F., Stasinskiy L. S. Chemistry of hydrides. Moscow: Khimiya, 1969. 676 p.

29. Davydova L. P., Popovskiy V. V., Bulgakov N. N. Study of processes of interaction of methane and ethane with surface of oxide catalysts. Kinetics and Catalysis. 1988. Vol. 29. No. 3. pp. 1162-1168.

30. Ormont B.F. Structure of inorganic substances. Moscow: Nauka, $1959.968 \mathrm{p}$.

31. Syrkov A. G., Kabirov V. R., Kavun V. S. Development of solid state hydride synthesis of surface-nanostructured disperse metals. Smart Nanocomposites. 2016. Vol. 7. No. 2. pp. 213-217.

32. Slinyakova I. B., Denisova T. I. Silicon-organic sorbents: obtaining, properties, application. Kiev: Naukova Dumka, 1988. 192 p.

33. Boynovich L. B. Superhydrophobicic coatings - new class of polyfuntional materials. Vestnik RAN. 2013. Vol. 83. No. 1. pp. 10-22.

34. Schellenberger F. How water advances on Superhydrophobic surfaces. Phys. Rev. Letter. 2016. Vol. 116. p. 096101. 
35. Roberts M., Makki Ch. Chemistry o metal-gas interface. Moscow: Mir, 1989. 359 p.

36. Pozhidaeva S.D., Ageeva L.S., Ivanov A.M. Comparative analysis of zinc and tin oxidation with acids at room temperatures. $\mathrm{Za}$ piski Gornogo instituta. 2019. Vol. 235. pp. 38-46.

37. Slobodov A. A., Syrkov A. G., Yachmenova L. A., Kushchenko A. N., Prokopchuk N. R., Kavun V. S. Effect of temperature on solid-state hydride metal synthesis according to thermodynamic modeling. Zapiski Gornogo instituta. 2019. Vol. 239. pp. 550-555.

38. Bazhin V. Yu., Vorobiev A. G., Beloglazov I. I. Professor Beloglazov as the founder of the process and plant automation department with Mining Institute. Tsvetnye Metally. 2020. No. 7. pp. 41-48.

39. Sizyakov V. M., Brichkin V. N. About the Role of Hydrated Calcium Carboaluminates in Improving the Technology of Complex Processing of Nephelines. Zapiski Gornogo instituta. 2018. Vol. 231. pp. 292-298.

40. Sizyakov V. M. Chemical and technological regularities of sintering processes of alkali aluminosilicates and hydrochemical processing of cakes. Zapiski Gornogo instituta. 2016. Vol. 217. pp. 102-112.
41. ElDeeb A. B., Brichkin V. N., Povarov V. G., Kurtenkov R. V. The activation effect of carbon during sintering the limestonekaolin mixture. Tsvetnye Metally. 2020. No. 7. pp. 18-25.

42. Petrov G. V., Shneerson Ya. M., Andreev Yu. V. Extraction of platinum metals during processing of chromium ores from dunnite deposits. Zapiski Gornogo instituta. 2018. Vol. 231 pp. 281-286.

43. Aleksandrova T. N., Heide G., Afanasova A. V. Assessment of refractory gold-bearing ores based on integration of thermal analysis data. Zapiski Gornogo instituta. 2019. Vol. 235. pp. 30-37.

44. Aleksandrova T. N., Afanasova A. V., Heide G., Noblich A. Investigation of the carbonaceous component of gold-bearing ores by means of thermal analysis. Innovation-based Development of the Mineral Resources Sector. Challenges and Prospects: proceedings of the 11th Russian-German Raw Materials Conference, Potsdam, November 7-8, 2018. p. 459

45. Bazhin V. Yu. 245 th anniversary of Mining University and its contribution to Russia's non-ferrous metals industry. Tsvetnye Metally. 2018. No. 10. pp. 61-68.

46. Dubovikov O. A. Scientific heritage of academician Nikolay Semenovich Kurnakov. Zapiski Gornogo instituta. 2015. Vol. 215. pp. 65-74.

V. A. Bocharov, V. A. Ignatkina

Technology of mineral processing

\section{in 2 volumes*}

- Mineral raw materials base

- TeChNology of RaRe metals processing

- TECHNOLOGY OF NON-FERROUS METALS PROCESSING

- TeCHNOLogy of RARE METALS PROCESSING

- Processing of gold-bearing ores and alluVIal deposits

- Processing of ferrous ores

- Processing of carbon group ores

- Processing of mining-Chemical and Non-metallic raw materials

- Production organization and management on PROCESSING PLANTS

Реклама

Advertisement

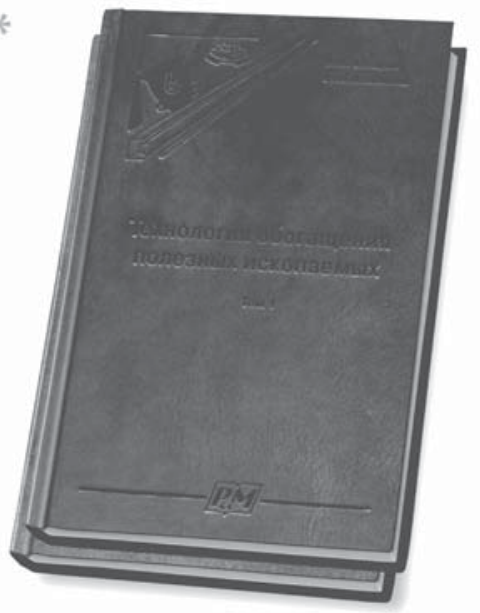

If you want order this book, you should send your request: P. O. Box 71, B-49, Moscow, 119049, Russia

Phone + 7(495) 955-01-75

E-mail: books@rudmet.com Internet: http://www.rudmet.com

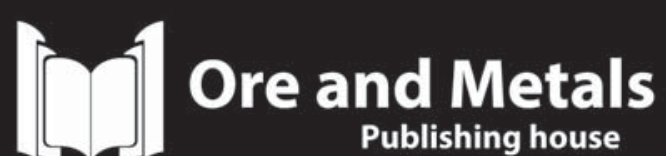

